\title{
Consumption patterns of non-steroidal anti-inflammatory drugs by the community without prescription in Dhaka city
}

\section{Md. Khoshroz Samad \\ 81 Field Ambulance, Mymensingh Cantonment, Mymensingh 2200, Bangladesh.}

\begin{tabular}{|c|c|}
\hline \multicolumn{2}{|l|}{ Article Info } \\
\hline Received: & 22 August 2008 \\
\hline Accepted: & 23 August 2008 \\
\hline Available Online: & 27 August 2008 \\
\hline \multicolumn{2}{|c|}{ DOI: 10.3329/bjp.v4i1.1065 } \\
\hline \multicolumn{2}{|c|}{$\begin{array}{l}\text { Cite this article: } \\
\text { Samad MK. Consumption patterns of } \\
\text { non-steroidal anti-inflammatory } \\
\text { drugs by the community without } \\
\text { prescription in Dhaka city. Bangla- } \\
\text { desh J Pharmacol. } 2009 ; 4: 43-45 \text {. }\end{array}$} \\
\hline
\end{tabular}

\section{Article Info} 23 August 2008

Available Online:

Abstract
A cross-sectional study on consumption patterns of non-steroidal anti-
inflammatory drugs (NSAIDs) by the community without prescription was
conducted in Dhaka Metropolitan City. A total of 608 encounters from 16
pharmacies were interviewed from people found to purchase drugs of the
pharmacy from their self demand. The commonest purchased NSAIDs per
encounter was paracetamol (37.0\%). Ibuprofen $(13.8 \%)$, diclofenac sodium
$(12.7 \%)$, aspirin $(7.4 \%)$, naproxen $(6.9 \%)$ and other group of NSAIDs $(22.2 \%)$
were also purchased. The influence by friends/relatives $(30.3 \%)$ previously
advised by the doctor to purchase the NSAIDs for the same complaint were
$(29.1 \%)$; pharmacy salesmen's advice ( $28.3 \%)$ and other reasons $(12.3 \%)$. The
total cost of purchased NSAIDs per encounter were less than Tk. $5(6.9 \%)$, Tk. 5
to less than Tk. 10 (45.4\%), Tk. $10-25$ ( $35.5 \%)$ and more than Tk. $25(12.2 \%)$.
Single item of drug was purchased along with NSAIDs by $17.1 \%$ of encounters.

\section{Introduction}

Fever and pain are usually the early symptoms of most of diseases. To cure and controls of these symptoms non-steroidal anti-inflammatory drugs (NSAIDs) have taken place in a large scale. To minimize the expenditure and hazards to consult with the physician and many more reasons people use to consume NASIDs by his own will throughout the world. As Dhaka is not only the capital city of Bangladesh, but also population crossed 11.2 millions (Turner, 2002) so it is a must to find out the patterns and magnitude of consummation of NSAIDs in this mass population. The production statement of the year 2002 of one of the leading companies of Bangladesh showed that total trade price of paracetamol tablets (500 mg) was Tk. 940,948.31. Almost all the drugs except narcotics were found to be sold in the market of Dhaka City without prescription (Ashraf and Bhuiyan, 2003). The prescribing pattern of NSAIDs in prescriptions prescribed by the qualified medical personnel in the Out-patient Departments of three selected teaching hospitals in Dhaka city were described (Rahman et al., 2007) .

\section{Materials and Methods}

The study was carried out in Dhaka city during July 2002 to June 2003. Thanas were selected by random method from the different parts of the city so that it can represent the whole population. Each two Thanas were selected randomly from Northern, Southern, Eastern and Western geographically part of Dhaka city. As a result eight Thanas were taken under study design. The researcher tried to find out and note down each and every pharmacies of each Thana. Now, from each Thana two pharmacies were selected by random method. As a result, total 16 pharmacies were selected for research. Total 608 encounters (who purchased NSAIDs without prescription) were interviewed by structured questionnaires from randomly selected pharmacies to enroll in the study. Data were processed, simplified, tabulated and analyzed by using SPSS software, version 10.0. 


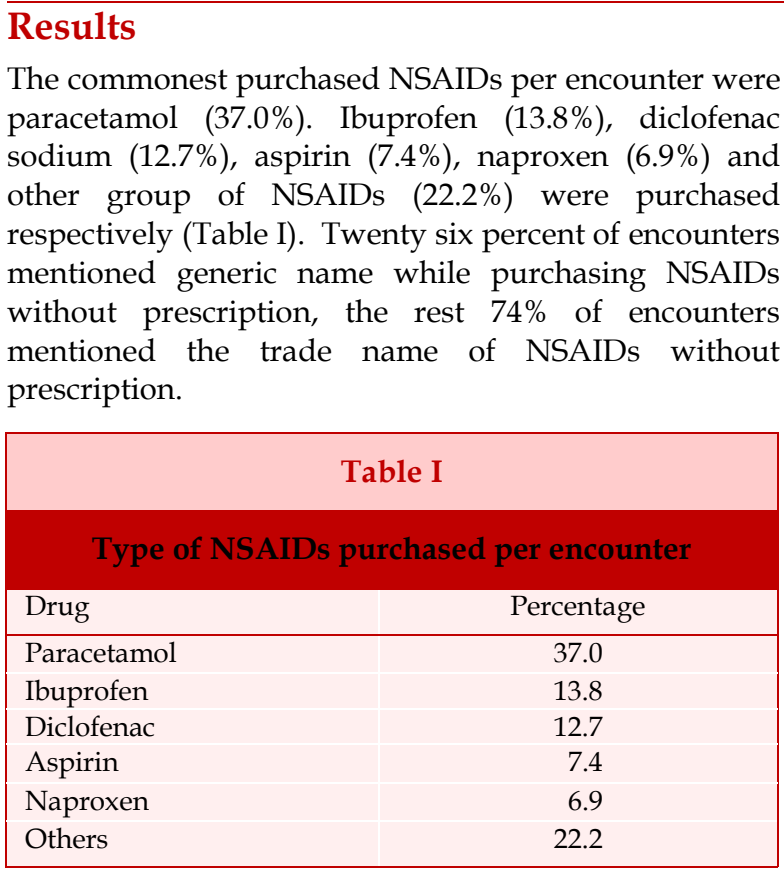

Age group of the encounters 'below 15 years' (8\%); 1545 years was $(81 \%)$; 'above 45 years' $(11 \%)$ respectively of total encounters. Among the 608 encounters, males were $74 \%$ and female were $26 \%$. The commonest occupation of the encounters was service $(27.1 \%)$. laborer (16.4\%); housewife (15.3\%); business $(11.7 \%)$; unemployed (11.3\%); student (10.5\%) and other occupational groups $(7.6 \%)$ were observed respectively. Education status of the encounters 'below S.S.C.' (38.0\%); S.S.C qualified (16.8\%); H.S.C.(25.0\%) 'graduate' $(11.2 \%)$; post-graduate $(9.0 \%)$ were observed.

Headache $(24.3 \%)$ was the commonest chief complaint of the encounters. Backache $(17.4 \%)$, traumatic injury $(16.6 \%)$, fever $(13.8 \%)$, sports injury $(7.1 \%)$, and other cause was mentioned $(21.4 \%)$ as the chief complaint of encounters.

Encounters were motivated to consume the NSAIDs without prescription. The influence by the friends/ relative $(30.3 \%)$ was the commonest reason behind to be influenced to consume NSAIDs without prescription. previously advised by the doctor to purchase the NSAIDs for the same complaint were (29.1\%); pharmacy salesmen's advice (28.3\%) behind to be influenced to consume NSAIDs without prescription.

The total cost of purchased NSAIDs per encounter were 'less than Tk. 5' (6.9\%); '5 to less Tk. 10' (45.4\%); which were almost half of total encounters; Tk. 10-25 (32.5\%) and 'more than Tk. 25' (12.2\%) (Table II).

History of exposure to traditional drugs were $36.1 \%$ and modern drugs were no history of exposure to traditional/modern drugs were $20.2 \%$ of total for the same complaint. Single item of drugs were purchased along with NSAIDs by $17.1 \%$ of encounters. $\mathrm{H}_{2}$ blockers

\begin{tabular}{|lc|}
\hline \multicolumn{2}{|c|}{ Table II } \\
\hline \multicolumn{2}{|c|}{ Total cost of purchased NSAIDs } \\
\hline Taka & per encounter \\
\hline Less than 5 & Percentage \\
$5-10$ & 6.9 \\
$10-25$ & 45.4 \\
More than 25 & 32.5 \\
\hline
\end{tabular}

(24.7\%); antacid (18.1\%); anti-histamine (10.9\%); antibiotic $(2.5 \%)$; other $(1.0 \%)$ and other group of drugs $(25.8 \%)$ were purchased along with by encounters.

\section{Discussion}

Almost all the drugs, except narcotics were found to be sold in the market of Dhaka city with or without prescriptions (Ashrafuzzaman and Bhuiyan, 2003). The commonest purchased NSAIDs per encounter were paracetamol $(37.0 \%)$. In one study in Philippine it was observed that, analgesics were extremely popular in the self medication of non-severe respiratory disorders, often being given three times a day (Hardon and Geest, 1987).

In another study in USA, regarding the safety of paracetamol and ibuprofen among children younger than two years old, Lesko and Mitchell (1999) observed that the risk of serious adverse effect clinical events among the children of 2 years old receiving short-term treatment with either paracetamol or ibuprofen suspension was small and did not vary by choice of medication. Now, it is the time to think about switching on ibuprofen from paracetamol, specially in short-term treatment for use in children even without prescription.

Twenty six percent of encounters mentioned generic name while purchasing NSAIDs without prescription. The popularity of brand name of paracetamol and aspirin in mass people has guided them for mentioning generic name.

Age group of the encounters $15-45$ years was $81 \%$ of total encounters. This is the working class of active people. Their highest incidence to consume NSAIDs may be due to their frequent nonspecific psychosomatic illness. But in one study it was observed that, selfadministration was wide spread, 58.3 to $75.9 \%$ of adolescents reported taking an OTC medication for pain. Adolescents reported that they began to selfadminister medication begun the age of 11 and 12 years (Chambers et al., 1997).

In one study in Sweden, Antonov and Isacson (1998) observed that among female, $30.4 \%$ reported nonprescription analgesic use, while corresponding proportion among make Among the 608 encounters, males were $74 \%$. The reason behind is that most of the women in Dhaka city are still house wives and hardly visit the shops for their own medications. But were $20.0 \%$ respectively. 
The commonest occupation of the encounters was service $(27.1 \%)$. Service included person serving in government, semi government, autonomous or private organizations. The frequent sickness among the service personnel due to their insecurity of job and professional stress. The laborers includes daily laborer, rickshaw pullers, garments workers, construction workers and industrial workers. As their nature of job required manual labor so, they used to suffer from different nonspecific musculoskeletal pain.

Regarding educational status it was observed that both literate and illiterate classes consume NSAIDs without prescription. In this study it was observed that encounters below SSC were 38\% while postgraduate encounters were 9\% of total encounters. But Quah (1985) observed in Singapore that self-medication increases with the person's level of education.

Pain is the commonest symptom that takes patient to doctor (Bennet and Brown, 2003). Headache (24.3\%) was the commonest chief complaint of the encounters , while fever was mentioned as chief complaint in 13.1\% of encounters, It was observed that encounter consult doctor/unqualified prescriber for quick remedy while in headache/nonspecific pain, encounters directly consume NSAIDs without prescription. Self-medication behavior for the treatment of headache is a widespread phenomenon with costly and hazardous consequences.

The influence by the friends/relatives (30.3\%) was the commonest reason to consume NSAIDs without prescription. In the minor ailment (like headache), patients usually discuss with his/her friends/relatives. The friends/relatives advised to consume NSAIDs to avoid the consultation fee of doctor and other associate expenditure. The influence by salesman (28.3\%) was one of the important reasons. Many drugs in developping countries are sold by untrained drug sellers who treat drugs as consumer items.

The cost of purchased NSAIDs was Tk. 5 to less than Tk. 10 in $45.4 \%$ of total purchased drugs. For short-term therapy and for symptomatic treatment encounter purchased NSAIDs within the above - mentioned limit. In addition to that, the another cause to take treatment facility in small budget may be poverty. For the most people in world today every step of life, from infancy to old age, is taken under the twin shadows of poverty and inequality, and under the double burden of suffering and disease (The World Health Report, 1995).

Twenty percent of encounters did not consume any medicine for that current symptom, while $36.1 \%$ of encounters received traditional medicine (homeopath/ ayurvedi) previously. It was observed that $\mathrm{H}_{2}$ blocker $(24.7 \%)$ or antacid $(18.1 \%)$ was purchased along with NSAIDs, to prevent gastric adverse effects. Antihistamine $(10.9 \%)$ and even antibiotic $(2.5 \%)$ were also purchased in case of fever and other infective conditions.

\section{Conclusion}

This study may only give a baseline data regarding the patterns and magnitude of consumption of NSAIDs only in Dhaka City. To get the profile the consumption of other OTC drugs without prescription and even other abuse-prone narcotics are needed to go for study in national level. An integrated plan may be designed to carry out study throughout the Bangladesh from grass root to top in this regard.

\section{Acknowledgements}

I feel proud that this study was carried out under guidance of Prof. Mir Misbauddin and Dr. Syedur Rahman of BSMMU, who inspired me to make the study successful. Colonel Md. Ashrafuzzaman and Lieutenant Colonel Abdul Karim Khan of AFMC gave their valuable suggestions and constructed criticism throughout the research work.

\section{References}

Antonov KI, Isacson DG. Prescription and non-prescription analgesic use in Sweden. Ann Pharmacother. 1998; 32: 48594.

Annonymous. Multicentre study on self medication and self prescription in six Latin American countries. Clin Pharmacol Ther. 1997; 61: 488-93.

Ashrafuzzaman M, Bhuiyan MAM. A study on selfmedication in a metropolition city. Bangladesh Armed Forces Med J. 2003; 31: 59-61.

Bennet PN, Brown MJ. Pain and analgesics. In: Clinical pharmacology. Bennet PN, Brown MJ (eds). 9 th ed. New York, Churchils Livingstone, 2003, pp 319-31.

Chambers CT, Reid GJ, Mcgrath PJ, Finley GA. Self adminstration of over-the-counter medication for pain among adolescents. Arch Pediatr Adolesc Med. 1997; 151: 449-55.

Hardon A, Geest SVD. Hazards of self-medication. World Health Forum. 1987; 8: 469-71.

Lesko SM, Mitchell AA. The safety of acetaminophen and ibuprofen among children younger than two years old. Pediatrics 1999; 104: 39.

Quah SR. Self-medication in Singapore. Singapore Med J. 1985; 26: 123-29.

Rahman MS, Begum ZA, Samad MK. Prescribing pattern of non-steroidal anti-inflammatory drugs at outpatient departments of teaching hospitals. Bangladesh J Pharmacol. 2007; 2: 1-6.

The World Health Report 1995: Bridging the gaps. World Health Forum. 1995; 16: 377-80.

Turner B. Bangladesh. The stateman's year book 2002. 138 th $\mathrm{ed}$. pp 264-65. 